Original Research Paper

\title{
Development of Health Informatics for Caring for Children in Occupational Therapy Service Communities
}

\author{
Kewalin Panyo, Supawadee Putthinoi and Suchitporn Lersilp \\ Department of Occupational Therapy, \\ Faculty of Associated Medical Sciences, Chiang Mai University, Chiang Mai, Thailand
}

\author{
Article history \\ Received: 21-06-2018 \\ Revised: $14-07-2018$ \\ Accepted: 24-07-2018 \\ Corresponding Author: \\ Suchitporn Lersilp \\ Department of Occupational \\ Therapy, Faculty of Associated \\ Medical Sciences, Chiang Mai \\ University Chiang Mai, \\ Thailand \\ Email: suchitporn.1@cmu.ac.th
}

\begin{abstract}
Health Informatics (HI) is an integration of health information and technology to be improving levels of efficiency in Occupational Therapy (OT) care managers in the community. The purpose of this study was to develop $\mathrm{HI}$ in the community for care managers caring for children from birth to 6 years old. Fifteen participants were occupational therapists, who worked as care managers in the community. The research instrument was a questionnaire that comprised 22 items in 4 aspects including requirement, function, usability and security. The HI system in this study comprised 6 parts such as log in, data display and summary, history, assessment, intervention and follow-up. Efficiency of the HI system was at the good level from the perspective of users $(4.30 \pm 0.58)$. When the efficacy of aspects was considered, the result found that usability was presented at the high level and had the highest mean, next to security, function and requirement, consecutively.
\end{abstract}

Keywords: Health Informatics, Care Manager, Community-Based Services, Children

\section{Introduction}

The current population in Thailand is about 63.50 million people, of which roughly 7.65 million are in the birth to 6 year-old age group (NICDF, 2011). The number in this age group is declining continually because of a dropping birth rate from $31.80 \%$ during 2001-2005 to an estimated $19.70 \%$ in $2026-2030$ (HIS, 2015). As Thailand will have become an aging society by 2064-2574 (Prasatkun, 2016), earlier child development is encouraged as a way to increase the quality of future human resources (Wungchanthanon et al., 2014). Therefore, the National Economic and Social Development Plan intends to encourage appropriate health services for children, which supports a healthy community system in all dimensions (ONESDB, 2017). However, health professionals in communities are limited. Health service providers, who work in communities have more than one role to play and they operate with community members as a team. Care managers play an important role in community hospitals in Thailand. They are responsible for providing primary health services such as developmental screening, home visiting, home programing, database recording and so on. Therefore, some health service providers have been health professionals and also care managers at the same time. Most care managers in Chiang Mai province are occupational therapists.

The Model of Human Occupation (MoHO) has the principle of applying human activity to community-based practice (Scaffa and Reitz, 2014). This model focuses on community change and describes its structures in the human system, of which there are two; the trajectory of change and adaptive and maladaptive cycles (Scaffa, 2001). The model can be applied to encourage community response, involvement and empowerment by analyzing internal needs such as identity, values and interests, as well as external environments, for instance, a physical and social environment. Health service providers have to participate in community-based service and promote community health by increasing community performance for making decisions and solving problems regarding health. This performance will develop into communitybased skills that strengthen the capacity of the community. In fact, community-based practices in health promotion, community knowledge and community participation make the community stronger with community members in good health (Solomon and Obrien, 2011).

Health Informatics (HI) is an integration of health information and technology that designs, develops and applies innovated information technology in public health services (Thiratsirikul and Caefan, 2010; Hebda et al., 
2005). In particular, evaluating and monitoring the health of a community population tends to use HI to develop effective service systems (Beck et al., 1998). In developing $\mathrm{HI}$ to be consistent with the context of healthcare delivery, it comprises three levels such as the operational, management and executive information system level (SISTH, 2013). In the 21st century, the national era of information technology is vital to the health care system by designing, developing and applying integrated health and technology information for health care services. This system can support health service providers in making decisions for evaluating, treating and following up health outcomes effectively (Yana and Sirapanitkul, 2015). The HI has been currently used in both written and electronic forms of management and stored as many medical information profiles per Thai hospitals. It needs to be more accurate data during the process of diagnosis and treatment plans by, reducing those duplicated data and improving efficient services (Triviriyanupab et al., 2013). As a result, the government recognized the importance of developing $\mathrm{HI}$ and has set a policy to reform the public health system and improve the quality of life for people in the community. In particular, health services for children in the community are termed as holistic child care, which is based on the understanding that all children could have various programs of potential enhancement (Yana and Sirapanitkul, 2015). Therefore, a development of information systems for children at birth to six years of age would be making a big change of better quality of life in a recognition of government policy.

The HI is studied quite widespread in medical and nursing professions with community hospitalized contexts of Thailand remains using structured forms of medical information system, which has focused on a decision making and organizing for national health promotion programs including a hospitalized client classification system (Kuntawong, 2007; Rimsuk, 2012). However, it rarely develops into other paraprofessionals such as Occupational Therapy (OT) services (Schaper and Pervan, 2007). Therefore, the purpose of this research was to develop HI in community-based services for OT in children from birth to 6 years of age. The HI system was based on using information management of assessment, intervention and follow-up on developing children in the communities toward accessible services gained in the community healthcare system and technology.

\section{Materials and Methods}

This research was approved by the Research Ethics Committee of the Faculty of Associated Medical Sciences, Chiang Mai University, Thailand (AMSEC61EX-008). There were two phases, with the first being development of the HI system that comprised two steps, i.e., (a) designing program contents and (b) developing the HI system. Indeed, before developing the HI system, its content and process was design by reviewing related literature (Naipat, 2005), expert examination and member checking. The second phase was an efficiency study of the HI system. In this phase, occupational therapists of the Chiang Mai Occupational Therapist Club were invited as care managers in their service communities to participate and investigate efficiency of the HI system. The inclusion criteria were (a) working as a care manager of occupational therapy in the communities, (b) working at least 1-years' experience in pediatric services in the communities under a government hospital at Chiang Mai province and (c) making a consent form signed for being a participant in this study. As a result, there were fifteen participants in this study, as shown in Table 1 . They conducted a trial session for 1 hour before evaluating efficiency of the HI system by using a questionnaire (Ubonsuk et al., 2013), which was a Likert scale that comprised 22 items in 4 aspects including requirement, function, usability and security. The interpretation level of efficiency in the HI system was classified into five levels as follows:

$\begin{array}{ll}\text { Mean } & \text { Level of the efficiency } \\ 4.50-5.00 & \text { High } \\ 3.50-4.49 & \text { Good } \\ 2.50-3.49 & \text { Medium } \\ 1.50-2.49 & \text { Low } \\ 1.00-1.49 & \text { Very Low }\end{array}$

Table 1: General information of the participants $(n=15)$

\begin{tabular}{lcc}
\hline General information & Numbers & Percentage \\
\hline Gender & 6 & 40.00 \\
Male & 9 & 60.00 \\
Female & & \\
Age (years) & 2 & 13.30 \\
Less than 26 & 9 & 60.00 \\
26-30 & 3 & 20.00 \\
31-35 & 1 & 6.70 \\
More than 35 & & \\
Organization & 11 & 73.30 \\
Community hospital & 2 & 13.30 \\
General hospital & 1 & 6.70 \\
Provincial hospital & 1 & 6.70 \\
Medical institute & & \\
Work experience & 2 & 13.30 \\
1-3 years & 4 & 26.70 \\
4 years & 9 & 60.00 \\
More than 4 years & & \\
Work experience in pediatrics & 5 & 33.34 \\
1-3 years & 4 & 26.66 \\
4 years & 6 & 40.00 \\
More than 4 years & & \\
Work experience in the community & 5 & 33.34 \\
1-3 years & 4 & 26.66 \\
4 years & 6 & 40.00 \\
More than 4 years & & \\
\hline
\end{tabular}




\section{Results}

\section{Development of the HI System}

The HI system was designed to have six parts such as $\log$ in, data display and summary, history, assessment, intervention and follow-up. The process of the system progressed from the log in to follow-up, as shown in Fig. 1.

After the text edit has been completed, the paper is ready for the template. Duplicate the template file by using the Save As command. In this newly created file, highlight all of the contents and import your prepared text file. You are now ready to style your paper.

The log in part is shown on the first page of the HI system. It comprises the name of the system, user ID box and password box (as shown in Fig. 2).

The data display and summary part shows the result of developmental screening, personal data and client status. In general, occupational therapists have the responsibility as care managers to screen the development of children in the community. The type of screening tool in this study depended on the birth weight. Children who had a low (< 2,500 grams) and normal ( $\geq 2,500$ grams) birth weight were screened for development by the Developmental Assessment For Intervention Manual (DAIM) and
Developmental Surveillance and Promotion Manual (DSPM), respectively. However, some communities had no occupational therapists in the community hospitals. Occupational therapists at the second and third level, in general and provincial hospitals or medical institutes, might be care managers in the community and use screening tools such as the DAIM and DSPM. Moreover, they were supposed to use the Thai Early Developmental Assessment for Intervention (TEDA4I) as a tool for helping preschool children with delayed development. For these reasons, the data display and summary part included results of the DAIM, DSPM and TEDA4I (Fig. 3).

The history part comprised general and health history. General history included national ID, name, name of caregiver, nationality, address, record date, birth date, gender, health scheme, hospital number, age and health condition. The health history included medical history, pregnancy history of mother and developmental screening record. Users of the developmental screening record were able to search the results of screening in the year the children were screened. The results of screening showed developmental areas in which the children were delayed such as Gross Motor (GM), Fine Motor (FM), receptive language (RL), Expressive Language (EL) and Personal-Social (PS) development (as shown in Fig. 4).

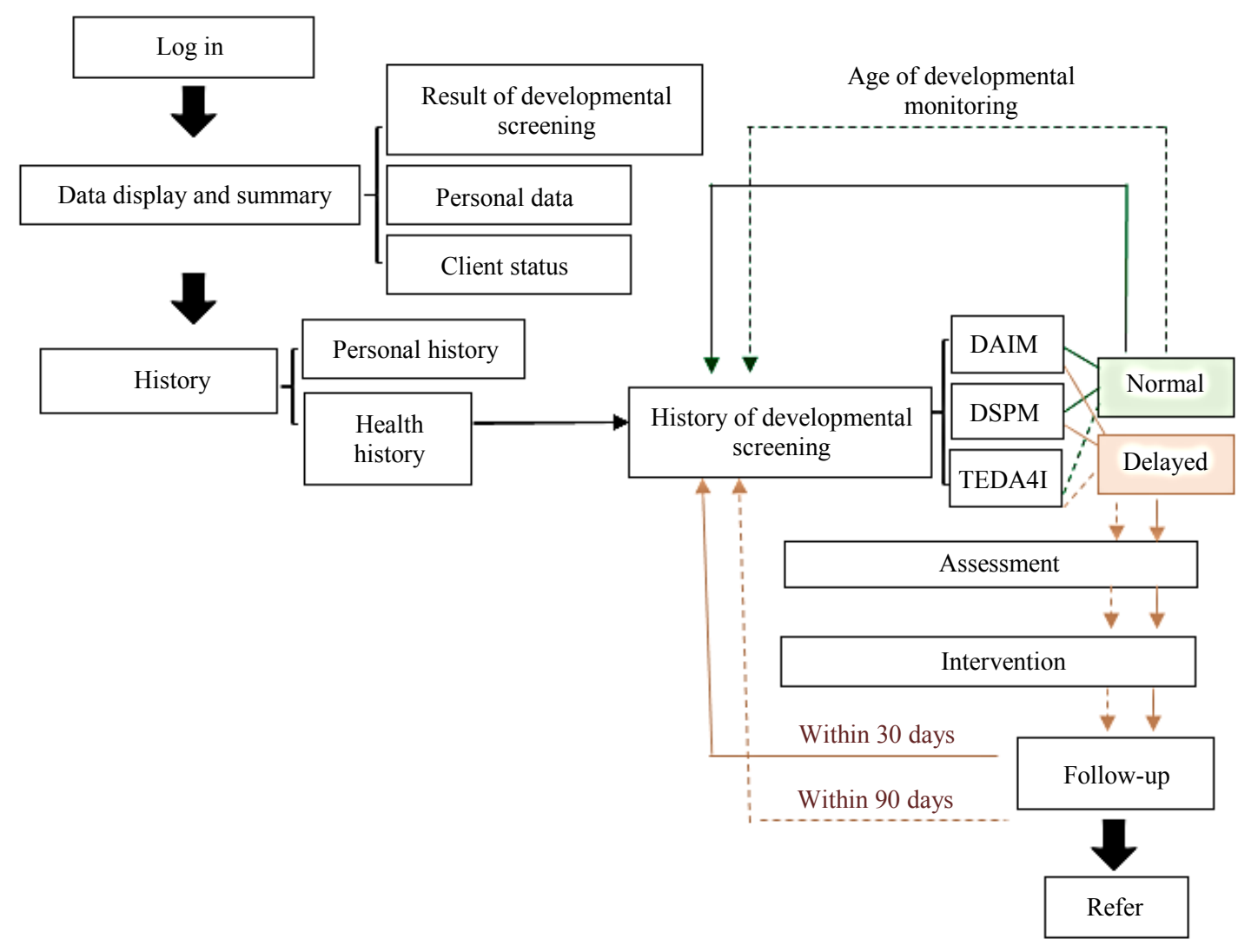

Fig. 1: Process of the HI system 


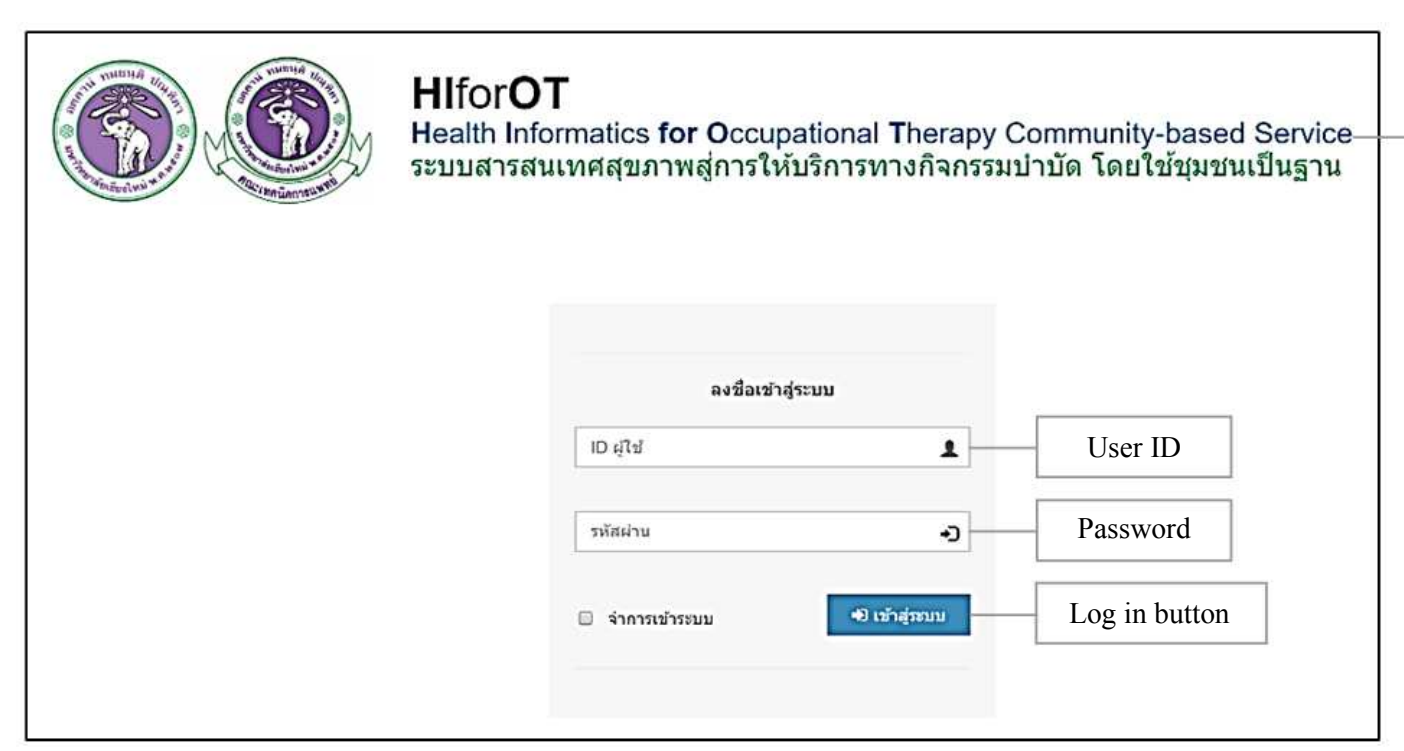

Fig. 2: The log in part

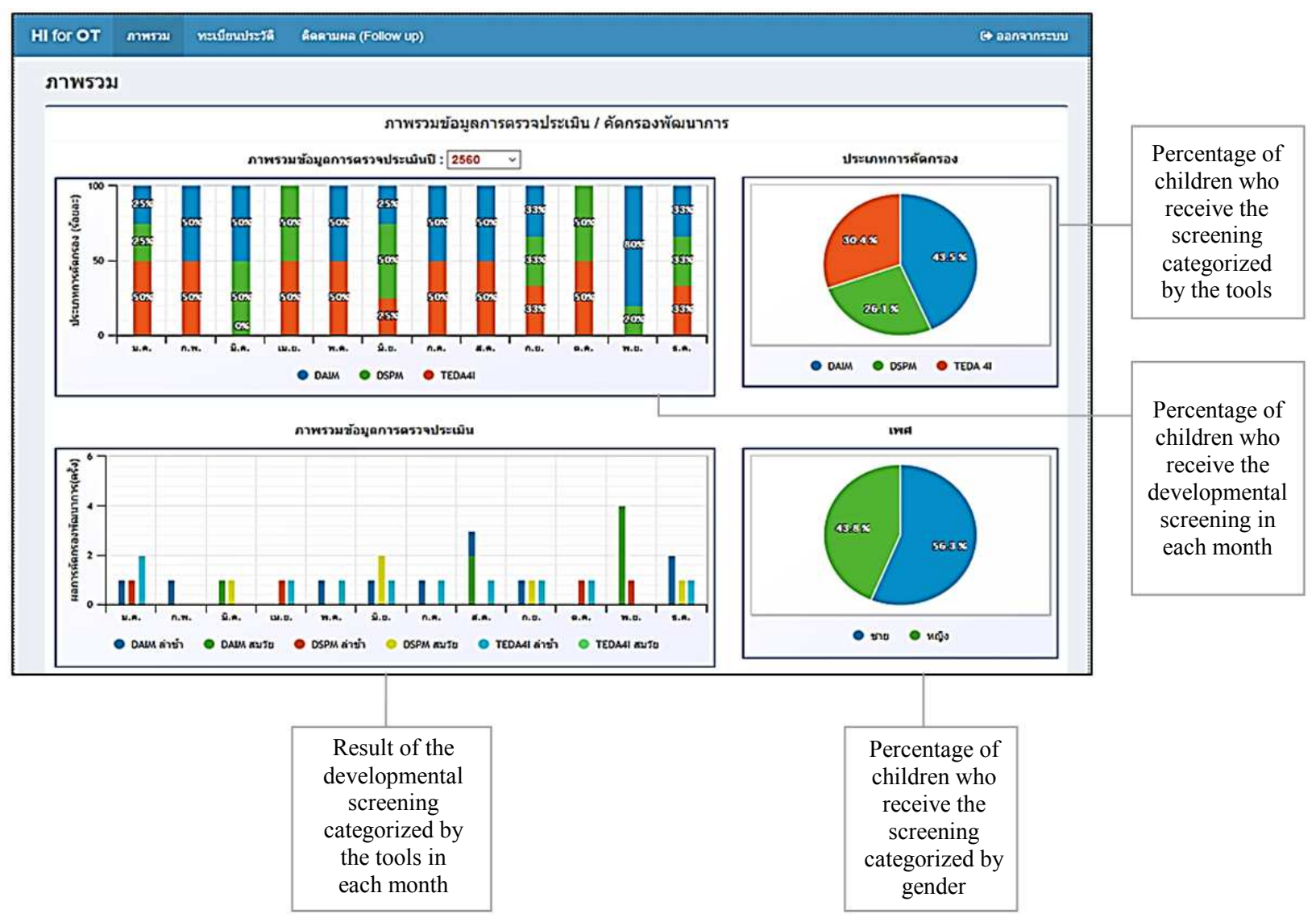

Fig. 3: The data display and summary part

The assessment part showed the assessment tools that care managers were able to choose. These tools related to the developmental areas in which the children were delayed. The lists of assessment tools in terms of GM
The name of HI system were The Miller Assessment for Preschoolers (MAP), Vineland Adaptive Behavior Scales (VABS), BruininksOseretsky Test of Motor Proficiency, Second Edition (BOT-2), Clinical Observation for Sensory Integration, 
Short Sensory Profile and Reflex Testing Chart. The lists of assessment tools in terms of FM were MAP, VABS, BOT-2, Developmental Test of Visual Perception, Second Edition (DTVP-2), Beery-Buktenica Developmental Test of Visual-Motor Integration, Sixth Edition (Beery-VMI), Motor-Free Visual Perception Test, Third Edition (MVPT-3), Dynamic Occupational Therapy Cognitive Assessment for Children (DOTCA-ch), Clinical Observation for Sensory Integration, Short Sensory Profile and Reflex Testing Chart. The lists of assessment tools in terms of RL were MAP, VABS, BOT-2, DTVP-2, BeeryVMI, MVPT-3, DOTCA-ch, Clinical Observation for Sensory Integration, Short Sensory Profile and Reflex Testing Chart. The lists of assessment tools in terms of EL were MAP, VABS, BOT-2, DTVP-2, Beery-VMI, MVPT-3, DOTCA-ch, Clinical Observation for Sensory Integration, Short Sensory Profile and Reflex Testing Chart. The lists of assessment tools in terms of PS were VABS, Short Sensory Profile and Reflex Testing Chart.

The intervention part comprised the intervention program, service code of the ministry and service code of the hospital. The care managers were able to choose the intervention program that suited the developmental problems of the children such as coordination and hand function training, oral-motor stimulation and training, perception and learning and pre-speech, sensorimotor component, sensory integration, BADL, IADL and preschool skill training (Fig. 5).

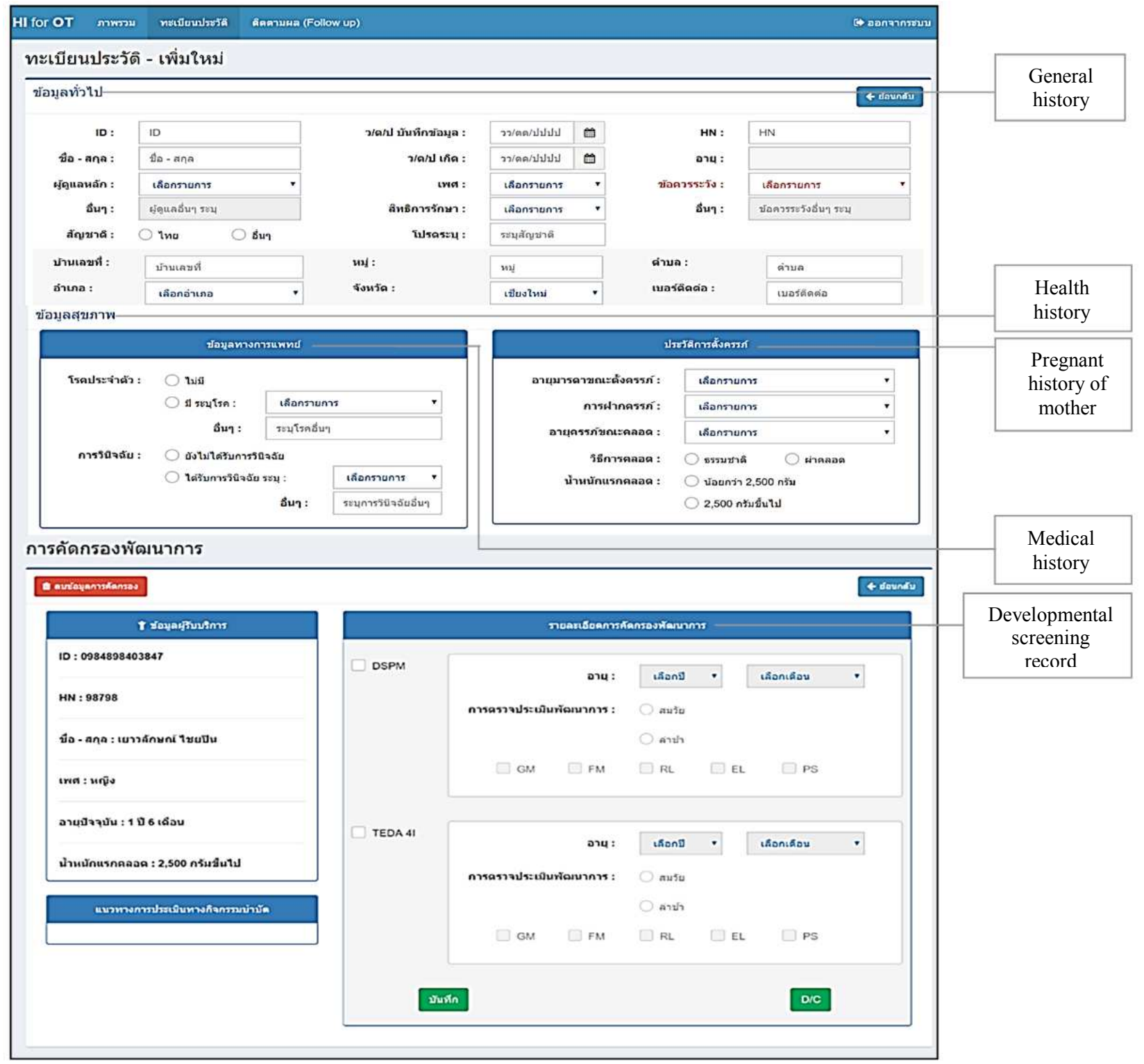

Fig. 4: The history part 


\begin{tabular}{|lcc|}
\hline Intervention Program & Service Code of the Ministry & Service Code of Hospital \\
\hline Coordination Training & $934-96-43,57101$ & $H 9383.1$ \\
\hline Hand Function Training & $726-96-52,57702$ & $H 9383.1$ \\
\hline Oral-motor Stimulation and Training & $927-96-01,57102$ & $H 9383.1$ \\
\hline Perception and Learning Training & $934-96-42,57903$ & $H 9383.1$ \\
\hline Pre-speech Training & $940-96-79,57909$ & $H 9383.1$ \\
\hline Sensorimotor Components Training & $935-96-45,57999$ & $H 9383.1$ \\
\hline Sensory Integration Training & $935-96-46,57999$ & $H 9383.1$ \\
\hline Basic Activity or Daily Living Training & $900-96-81,57001$ & $H 9383.1$ \\
\hline Instrumental Activity of Daily Living Training & $900-96-81,57999$ & $H 9383.1$ \\
\hline
\end{tabular}

Fig. 5: The intervention part

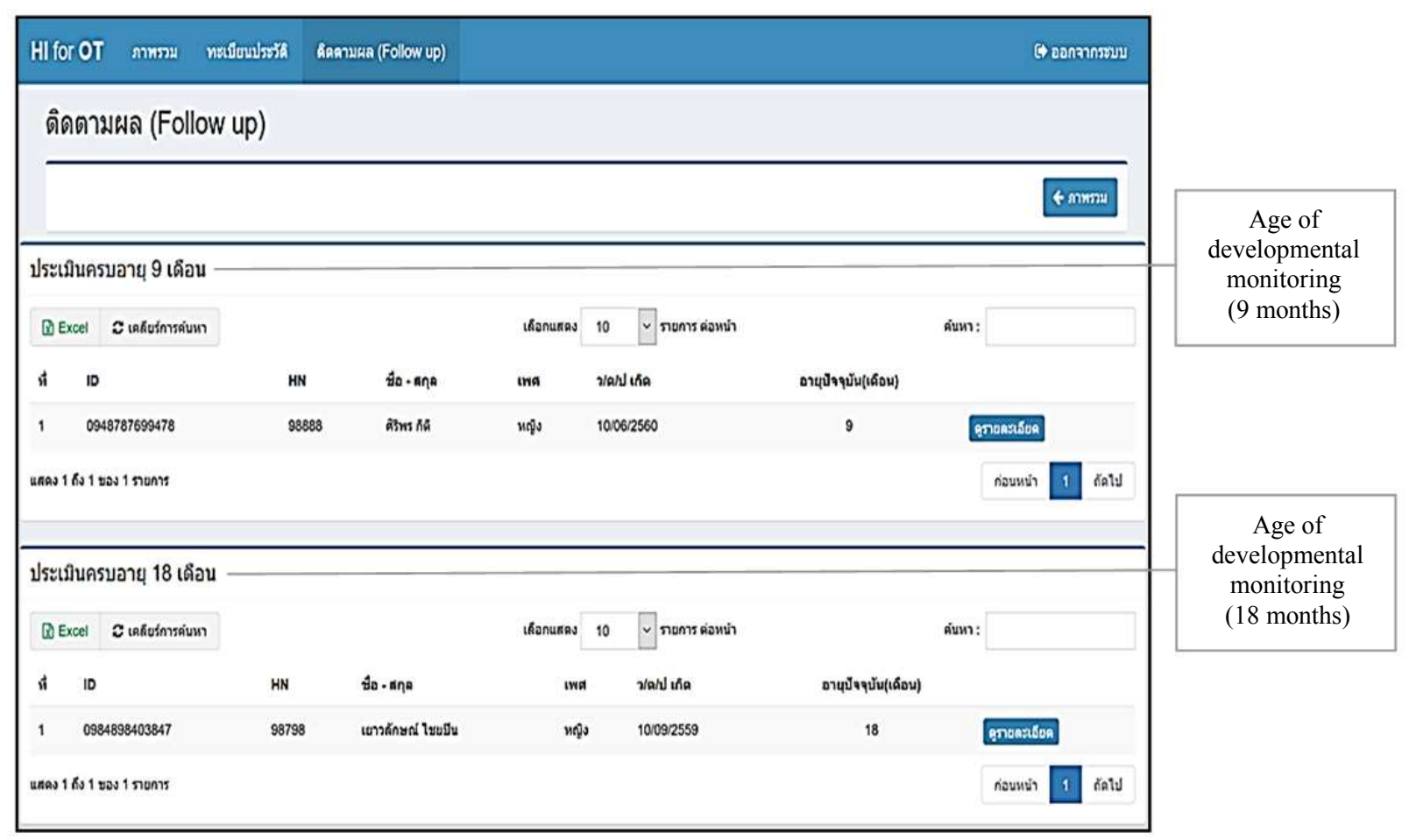

Fig. 6: The follow-up part

The follow-up part was set to alert care managers to re-screen the development of children when they were at the age of developmental monitoring such as 9 months, 18 months, 30 months and 42 months (Fig. 6). 
Table 2: Efficiency of the HI system $(\mathrm{n}=15)$

\begin{tabular}{lcc}
\hline Opinion on efficiency & $\overline{\mathrm{X}} \pm \mathrm{SD}$ & Interpretation \\
\hline Requirement & $4.15 \pm 0.54$ & Good \\
User management & $4.20 \pm 0.56$ & Good \\
Data management & $4.33 \pm 0.48$ & Good \\
Information alert management & $3.93 \pm 0.59$ & Good \\
Function & $4.19 \pm 0.59$ & Hood \\
Validation of data storage & $4.53 \pm 0.63$ & High \\
Validation of data editing & $4.53 \pm 0.51$ & High \\
Validation of data processing & $4.53 \pm 0.63$ & Good \\
Speed of data processing & $4.13 \pm 0.63$ & Good \\
Reliability of data processing & $4.06 \pm 0.59$ & Good \\
Compatibility between the HI system and health service system & $3.66 \pm 0.48$ & Good \\
Error of prevention & $3.93 \pm 0.70$ & High \\
Usability & $4.52 \pm 0.52$ & Good \\
Simple to use & $4.26 \pm 0.45$ & High \\
Type of Font & $4.53 \pm 0.51$ & Good \\
Size of font & $4.40 \pm 0.73$ & High \\
Color of font & $4.53 \pm 0.51$ & High \\
Data display and summary & $4.66 \pm 0.48$ & High \\
Components of data display & $4.66 \pm 0.48$ & High \\
Simple words/understandable technical terms & $4.66 \pm 0.48$ & Good \\
Security & $4.36 \pm 0.67$ & Good \\
Setting of user's status & $4.33 \pm 0.72$ & Good \\
Protection of privacy data & $4.40 \pm 0.63$ & Good \\
Total & $4.30 \pm 0.58$ & \\
\hline
\end{tabular}

\section{The efficiency of the HI system}

After the HI system trial, the participants gave their opinion on its efficiency. Results from the perpective of the users indicated that HI efficiency was at the good level. When the aspects of efficacy were considered, the result found that usability showed the highest mean $(4.52 \pm 0.52)$ and was presented at the high level, next to security, function and requirement, consecutively (Table 2).

\section{Discussion}

HI for care managers of children from birth to 6 years of age in the community was designed in this study from literature reviews, expert advice and member checking. That is to say, the development of HI was considered under policies of the Ministry of Health and context of the management system of community hospitals that are at the primary care service level (SISTH, 2013). Also, it related to the current situation of community health systems. Moreover, in designing the program, community-based practice was applied with adapted MoHO, which is the service practice and model for analyzing the internal and external needs for encouraging community participation (Scaffa, 2001). Thus, the HI system was expected to improve work effectively for health service providers at primary care hospitals and increase the quality of life for children in the community (SISTH, 2013; Yana and Sirapanitkul 2015). This issue related to Kaewyoo (2007), who found that the development of information systems by analyzing data in current situations was able to reduce the work process and increase work production more effectively. There is a tendency to use information systems in nursing to make work easier and be an important tool for the provision of health services, particularly in the health service area (Rimsuk, 2012).

In terms of efficiency, results of the prototype HI showed that it was at the good level after trialing the participants. This was because HI was developed for the needs of the users, who were occupational therapists working as care managers and having experience in providing services for children in the community. These care managers faced up to the problems of data overload and realized the usefulness of the HI system in improving the efficiency of health services in the public health system (SISTH, 2013). When considering each aspect of efficiency, the results found that usability was at the high level and had the highest mean. This was because the content of data recorded used general language and familiar technical terms of the health service. In addition, the data display was designed to be similar to that of the medical record system. Therefore, the participants noticed that the HI system was simple, easy to use and understandable. All of the other aspects (Table 2) were at the good to high levels. The HI program also provides security in accessing information by filling in a username and password before logging in. This process was checked the status and rights of the user. By setting up a user ID and unique password, the user would feel satisfied with 
the privacy and security of the data (Sunitsawan, 2012). Furthermore, the function of recording who and when the individual client accesses the data might be added, which would increase data privacy and security of the HI system.

Although the efficiency of the HI system were at the good level, the three lowest means were compatibility between the HI system and health service system, error of prevention and information alert management. This is because development of the HI system in community hospitals was at the primary care level, which is new in Thailand (Triviriyanupab et al., 2013) and the main health service system still does not support the hi-tech system. As seen some limitations, this HI system was studied within local areas, so that it was unable to be connected in between different areas and caring levels hospitals. Thus, complications in the main program of each hospital limited data alert management between them. However, further study might reflect the results of this study to related policy makers and make them aware and support this system. When the HI system is made to be managed easily and more completely, it will bring about active use for the user (Eungwattana et al., 2015).

\section{Conclusion}

The HI system was developed in this study and comprised six parts including log in, data display and summary, history, assessment, intervention and followup. Efficiency of the prototype HI system was trialed and opinions were given from fifteen occupational therapists, who worked as care managers for children from birth to 6 years of age in the community. Most of the participants were female and aged 26-30 years old and had more than 4 years' experience of pediatrics in the community. Their perspectives indicated that efficiency of the HI system was at the good level. Furthermore, the usability aspect was at the high level. The results of this research could be reflected in order to push for a future community health policy that improves the community health service system. However, this research has the limitation of applying $\mathrm{HI}$ in different contexts, because the study was conducted in a specific area.

\section{Acknowledgement}

The authors gratefully acknowledge funding support from the Graduate School, Chiang Mai University and Faculty of Associated Medical Sciences, Chiang Mai University, Thailand. The authors also wish to thank the occupational therapists who participated in this research.

\section{Funding Information}

This research was funded by the Graduate School, Chiang Mai University and Faculty of Associated Medical Sciences, Chiang Mai University, Thailand.

\section{Author's Contributions}

Kewalin Panyo: Reviewed the literature, designed the research, collected and analyzed the data and developed the manuscript.

Supawadee Putthinoi: Provided advice on the research design and approved the manuscript.

Suchitporn Lersilp: Provided advice on the research design, approved and analyzed the data and developed and approved the manuscript.

\section{Ethics}

This research was approved by the Research Ethics Committee of the Faculty of Associated Medical Sciences, Chiang Mai University, Thailand (AMSEC61EX-008).

\section{References}

Beck, R., V.J. Peel, D. Protti, A. Chairman and W.J. Towle, et al., 1998. Imformatrics and telematics in health: Present and potential uses. Switzerland.

Eungwattana, S., W. Teuanrat and W. Bunchiang, 2015. Development of a family health database of Public Health Nursing in Faculty of Nurse, Chiang Mai University. Chiang Mai University, Chiang Mai, Thailand.

HIS, 2015. Public health statistics A.D.2015: Bureau of policy and strategy. Health Information Section, Sam Charoen Commercial Co., Ltd, Bangkok, Thailand.

Hebda, T., P. Czar and C. Mascara, 2005. Handbook of Informatics for Nurses and Health Care Professionals. 3rd Edn., Prentice Hall, Upper Saddle River, NJ., ISBN-10: 0131512625, pp: 464.

Kaewyoo, V., 2007. Development of information system for research projects tracking. MSc Thesis, Chiang Mai University, Chiang Mai, Thailand.

Kuntawong, B., 2007. Development of a personnel health information technology system. MSc Thesis, Chiang Mai University, Chiang Mai, Thailand.

Naipat, A., 2005. Quantitative and qualitative research methods in behavioral science and social sciences. Samlada Partnership Limited, Bangkok, Thailand.

NICDF, 2011. Situations and concepts of children and youth. National Institute for Child Development and Family.

ONESDB, 2017. Summary of the 12th national economic and social development plan in 20172021. Office of The National Economic and Social Development Board, Bangkok, Thailand.

Prasatkun, P., 2016. The situation of thai elderly in 2015. Amarin Printing and Publishing Co., Ltd, Bangkok, Thailand. 
Rimsuk, R., 2012. Development of a patient classification database system for impatient unit. MSc Thesis, Chiang Mai University, Chiang Mai, Thailand.

Scaffa, M. and S.M. Reitz, 2014. Occupational Therapy Community-Based Practice Settings. 2nd Edn., F.A. Davis, Philadelphia, USA.

ISBN-13: 0803640730, pp: 478.

Scaffa, M., 2001. Occupational Therapy in CommunityBased Practice Setting. 2nd Edn., F.A. Davis, Philadelphia, USA. ISBN-10: 0803605595, pp: 414.

Schaper, L.K. and G.P. Pervan, 2007. ICT and OTs: A model of information and communication technology acceptance and utilisation by occupational therapists. Int. J. Med. Informat., 76: S212-S221. DOI: 10.1016/j.ijmedinf.2006.05.028

Solomon, J. and J. Obrien, 2011. Pediatric Skills for Occupational Therapy Assistants. 3rd Edn., Elsevier/Mosby, St. Louis, Mo., ISBN: 0323059104, pp: 630.

SISTH, 2013. Thai Health Information System. The Secretariat of the Senate. Subcommittee on Information Systems of Thai Health, Bangkok, Thailand.

Sunitsawan, M., 2012. An evaluation of information system usages. MSc Thesis, Chiang Mai University, Chiang Mai, Thailand.
Thiratsirikul, D. and K. Caefan, 2010. Health informatics.

Triviriyanupab, P., P. Saengwongngam, A. Saengarun and K. Sripimanwat, 2013. World health information system survey to intelligent systems development, Thailand 2010. National Science and Technology Development Agency: Pathumthani, Thailand.

Ubonsuk, T., P. Wongthong and P. Rachata, 2013. Development of information system for student clubs. Rajamangala University of Technology Suvarnabhumi, Nonthaburi, Thailand.

Wungchanthanon, T., S. Watthamamorn, N. Buntumporn and N. Jirarattanawan, 2014. The role of caregivers of early childhood development centers in screening and promotion of child development. J. Sci. Technol., 12: 114-121.

Yana, T. and R. Sirapanitkul, 2015. Community health system development guide with local health insurance fund. Sahamit Printing and Publishing Co., Ltd, Nonthaburi, Thailand. 